\title{
Studying the Relationship Between Body Mass Index, Waist-Hip Ratio and Quality of Life Among Adult Saudi Females
}

\author{
Bahiga Galal Abd El-Aal \\ Community Health Nursing Department, Faculty of Nursing, Menoufiya University, Shebin El-kom, Egypt
}

\section{Email address:}

b.s.a.m1963@gmail.com

\section{To cite this article:}

Bahiga Galal Abd El-Aal. Studying the Relationship Between Body Mass Index, Waist-Hip Ratio and Quality of Life Among Adult Saudi Females. American Journal of Nursing Science. Vol. 5, No. 6, 2016, pp. 251-257. doi: 10.11648/j.ajns.20160506.13

Received: October 3, 2016; Accepted: October 21, 2016; Published: November 15, 2016

\begin{abstract}
Overweight and obesity are received a great concern and becoming a high priority globally. Obesity is associated with diversity of health problem as well as decline in quality of life. This study was designed to estimate the prevalence of obesity; the association between body mass index, waist-to-hip ratio and quality of life. The design used in this study was descriptive correlational design. Study subjects were convenience samples of 310 adult female recruited from female colleges in Wadi Addawasir. The data was collected using self-administered questionnaire that consisted of socio-demographic data, participants' weight perception, World Health Organization Quality of Life-Brief (WHOQOL-Brief) and anthropometric measurements included weight, height, waist circumference, hip circumference. The main findings of this study indicated that the prevalence of general obesity according to BMI was $29.7 \%$, and abdominal obesity according to WC, and WHR were $34.2 \%$ and $35.5 \%$, respectively. A statistically significant difference between participants' weight perception and the existing BMI, $\mathrm{X}^{2}=50.52, \mathrm{P}=0.00$, indicated participants misperception of their weight. The mean total score of WHOQOL-Brief scale was $(70.01 \pm 11.31)$ and social relationships domain was the highest score, the mean $=73.02 \pm 17.10$, while lowest score was psychological domain, the mean $=64.76 \pm 13.73$. Moreover, $32.3 \%$ of subjects good quality of life, while only $3.9 \%$ had poor quality of life. A significant negative correlation was revealed between BMI, WC, WHR and total score of quality of life, $\mathrm{p}=$ $.012, .033, .012$ respectively. Moreover, the participants with increased BMI had decreased quality of life compared to those of normal BMI F = 3.209, $\mathrm{P}=.023$. Conclusion: General and abdominal obesity were highly prevalent among adult Saudi females as measured by BMI, WHR. Misperception of weight was revealed and minority of subjects had good quality of life. Obesity was associated with significant decrease in quality of life. Recommendation: Effective health education strategies are required to help in increase females' awareness and perception of their weight, thus affecting their decisions and behaviors to minimize obesity and its negative influences on their health and consequently their quality of life.
\end{abstract}

Keywords: Obesity, World Health Organization Quality of Life-Brief, Weight Perception, Body Mass Index, Waist Circumference, Waist-Hip Ratio

\section{Introduction}

Obesity and overweight have become a worldwide public health threat affecting $30 \%$ of the adult people. The prevalence of obesity among adult women from the United States is $35.5 \%$ [1]. Increasing rate of obesity in developing countries has become remarkable [2]. In the Kingdom of Saudi Arabia (KSA), obesity and overweight are expected to be increasing specially among females [3]. The expected increases may be due to the development in standards of living, decrease in activity level, unhealthy eating habits and other life style behaviors that leading to weight gain. The prevalence of overall obesity was of $35.5 \%$, while among females, it was $28.4 \%[4,5]$.

Overweight and obesity have various unfavorable impacts on the women's health. Overweight and obese are predisposing factors for increased risk of diabetes, hypertension, hyperlipidemia, heart diseases, low back pain, 
knee osteoarthritis, cancer, endocrine problems [6-9]. Moreover, obesity negatively affects contraception, fertility, breast feeding, rates of cesarean section, as well as many other obstetrical conditions. Furthermore, obese women are at increased risk of depression as well as many types of cancer including breast, endometrial, cervical, and ovarian cancer [10]. In Saudi Arabia, obesity is main risk factor for diabetes, hypercholesterolemia, and hypertension [11].

Body mass index (BMI) is calculated by dividing body weight in kilograms by height in meters the square. Body mass index is considered as the most convenience, safe, and cost effective widely used techniques for adult population to estimate the prevalence of overweight and obesity, in addition, identifying individuals' level of risk [12]. With increasing emphases on obesity detection, especially central obesity, waist circumference and waist-hip- ratio are basic measures that recently used to measure central obesity [1315]. Evidence from meta-analysis of studies had found association between waist circumference, waist-hip- ratio and cardiovascular diseases [16].

Quality of life (QOL) is the individual's perception of his or her position in life within the context of the culture and value systems in which he or she lives and relative to his or her objectives, expectations, patterns, and preoccupations [17]. The relation between obesity and quality of life are multidimensional [18]. Obesity and overweight are associated with many health problems that have a negative effect on different domains of quality of life [19 - 21]. Some studies indicated interaction between obesity and QOL [2224]. In KSA, few studies were carried out about the relationship between BMI and quality of life. A study conducted about the relationship between BMI and quality of life among female adolescence [25]. Another study conducted about physical health status and quality of life among older adults [26]. Therefore, the present study was carried out to estimate the prevalence of obesity based on body mass index (BMI), waist circumference, and waist-tohip ratio; and investigate the relationship between body mass index, waist circumference and waist-to-hip ratio and quality of life among adult Saudi Females.

\section{Aim of the Study}

Estimate the prevalence of obesity and investigate the relationship between body mass index, waist circumference, waist-to-hip ratio and quality of life.

\section{Research Questions}

(1). What is the prevalence of obesity in adult Saudi females?

(2). How the adult Saudi females perceive their weight?

(3). How the adult Saudi females score their quality of life?

(4). What is the relationship between BMI, waist circumference, and waist-to-hip ratio as measures of obesity and quality of life?

\section{Subjects and Methods}

\subsection{Design}

A descriptive correlational design was used in this study

\subsection{Subjects}

The subjects of the study were convenience sample of 310 non-pregnant Saudi nationality females, age range 20 to 60 years, not subjected to any therapeutic method of weight control. The subjects were recruited from female colleges in Wadi Al-Dawasir (K.S.A) from september-2015 to Jan 2016. The subject with chronic diseases and pregnancy were excluded from the study.

The subjects who met the study criteria were asked to complete self-administered questionnaire. Any questions or inquiries about the questionnaire and the study were clarified by the researcher. The confidentiality of participants' data was assured; after detailed explanation of the purpose and the nature of the study that was provided by the researcher. Informed consent was obtained from each subject accept to participate in the study.

\subsection{Tool of the Study}

Structured self-administered questionnaire was used for data of this of study.. The questionnaire included three parts. Part 1: socio-demographic data as age, education level, marital status, occupation, living situation. This part is ended by a question about how the participant perceived their weight. This question included four responses (underweight, normal weight, overweight and obese). The participants' responses used to assess their perception about their weight when compared with actual measurement of weight. Part 2: Arabic version of WHOQOL-Brief self-administered questionnaire that developed by WHOQOL group, 1998, was used to evaluate the quality of life for each participant. WHOQOL-Brief consists of 26 questions that represented four domains of quality of life. These four domains were physical health domain included 7 items, psychological domain included 6 items, Social relationships domain included 3 items, and environmental domains included 8 items. The other 2 items was used to represent the overall quality of life and general health. Each question has five responses scored from 1-5 (1, 2, $3,4,5) 1$ indicated lower score and 5 indicated higher score [27]. This score was transformed to a 0 to 100 scale in five responses $(0,25,50,75$, and 100), according to WHOQOL Manual-Body, 2005, to be used for interpretation and comparison [28]. Part 3: Anthropometric measurements included weight, height, waist circumference, hip circumference were measured to be used for assessing obesity.

According to WHO protocol, 2008, weight was measured using calibrated digital scale for each subject without shoes and with light wear. Height was measured using non stretching tape measure for each barefoot participant. Weight and height for all subjects were measured using the same instruments. Waist circumference was measured using non stretching tape measure at the level of umbilicus, midpoint between the lower 
margin of the last rib and the top of the iliac crest. The subject was in the standing position, arms at the side and with light wear. Hip circumference measured using non stretching tape measure around the widest portion of the buttocks. The subject was in standing position with feet close together, arms at the side and with light wear. Waist and hip measurement were used to calculate Waist-to-hip ratio (WHR) by dividing waist measurement by hip measurement $(\mathrm{W} / \mathrm{H})$ [29].

Weight and height were used to calculate Body mass index (BMI) by dividing weight in kilograms by the square of height in meter. According to the Report of a WHO Consultation on Obesity, 1998, the cut-off points that used to classify BMI were underweight (less than $18.5 \mathrm{~kg} / \mathrm{m}^{2}$ ), normal weight $\left(18.5-24.9 \mathrm{~kg} / \mathrm{m}^{2}\right)$, overweight $(25.0-29.9$ $\left.\mathrm{kg} / \mathrm{m}^{2}\right)$, obese $\left(30.0 \mathrm{~kg} / \mathrm{m}^{2}\right.$ and over). For WC, the cut-off points were $<80 \mathrm{~cm}$ for normal weight, $80-87.9 \mathrm{~cm}$ for overweight, and $\geq 88 \mathrm{~cm}$ for obesity. While the cut-off points for WHR were $<0.80$ for normal weight, $0.80-0.84$ for overweight, and $\geq 0.85$ for obesity [30].

The reliability of questionnaire used for data collection was tested on the data of 20 subjects that exclude from the study. Reliability cronbach's Alpha $=0.89$.

\subsection{Data Analysis}

Statistical analysis was carried out for the data collected from 310 subjects who completed the data collection tool. The data was coded, entered, and cleaned, then analyzed using SPSS version 17.0 statistical software packages. Descriptive statistics in the form of frequencies and percentages mean and standard deviation was to represent quantitative variables and number and percent for qualitative variables. Chi-square test used to compare categorical variables. Pearson correlation coefficient was used to test the association between BMI, WC, HC, and WHR, and rating quality of life score item and total score of quality of life. ANOVA test was used to compare mean of total score of quality of life and BMI categories, followed by Post hoc tukey test to find which of MBI categories were differed in mean total score of quality of life. Statistical significant was considered, if $\mathrm{P}$ value $<0.05$.

\section{Results}

The study sample was 310 female subjects who agreed to participate in the study and who provided complete data. The data collected was used to estimate the prevalence of obesity and examine the relationship between body mass index, waist circumference and waist-to-hip ratio and quality of life.

Table 1. Socio-demographics Characteristics of the Study Population $(n=310)$.

\begin{tabular}{lll}
\hline Participant characteristics & Frequency & Percent \\
\hline Age: & & \\
20- & 212 & 68.4 \\
30 - & 62 & 20.0 \\
$40+$ & 36 & 11.6 \\
Mean \pm SD & $28.27 \pm 7.89$ & \\
Educational level: & & \\
Middle school & 9 & 2.9 \\
High school & 23 & 7.4 \\
Bachelor students & 207 & 66.8 \\
University graduates and post & 71 & 22.9 \\
Material status: & & \\
Single & 175 & 56.5 \\
Married & 114 & 36.8 \\
Divorced & 20 & 6.5 \\
Widowed & 1 & .3 \\
Occupation & & \\
Employee & 103 & 33.2 \\
Students & 207 & 66.8 \\
Living situation: & & \\
Nuclear family & 250 & 19.35 \\
Extended family & 60.65 \\
Rating personal Weight & & \\
Underweight & 75 & 24.2 \\
Normal weight & & 26.8 \\
Over weight & & \\
Obese & & \\
\hline & & \\
\hline
\end{tabular}

Socio-demographics characteristics of study subjects are shows in table 1, more than two thirds of subjects 212 $(68.4 \%)$ were younger than 30 years of age, with mean age of 28.27 \pm 7.89 years. About two thirds of subjects 207 (66.8\%) were bachelor level of education, more than have of them were single $(56.5 \%)$, only $(33.2 \%)$ were employee and $(66.8 \%)$ were students. The majority of participant 250 $(80.65 \%)$ live in nuclear family. Regarding the participant perception of their weight, $24.2 \%$ and $26.8 \%$ of subjects describe their weigh as overweight and obese respectively.

Table 2. Prevalence of overweight and obesity among study population, based on body mass index, waist circumference, and waist -hip ratio.

\begin{tabular}{llllll}
\hline & BMI & & WC & \multicolumn{2}{c}{ Waist-hip ratio } \\
\cline { 2 - 5 } & No & \% & No & \% & No \\
\hline Underweight & 18 & 5.8 & & & \\
Normal weight & 107 & 34.5 & 121 & 39.0 & 130 \\
Over weight & 93 & 30.0 & 83 & 26.8 & 70 \\
Obese & 92 & 29.7 & 106 & 34.2 & 110 \\
Rang & $16.73-58.75$ & & $57.00-130.00$ & $.60-1.21$ \\
Mean \pm SD & $27.12 \pm 6.30$ & & $82.60 \pm 12.87$ & 35.5 & $0.82 \pm 0.82$ \\
\hline
\end{tabular}

Table 2 illustrate an estimation of the prevalence of overweight and obesity according body mass index, waist circumference, and waist -hip ratio. Based on BMI, the prevalence of overweight and obesity were $30.0 \%$ and $29.7 \%$ respectively, with mean BMI $27.12 \pm 6.30 \mathrm{~kg} / \mathrm{m}^{2}$, which 
indicating general obesity. The prevalence of overweight and obesity based on WC were $26.8 \%$ and $34.2 \%$ respectively, with mean WC $82.60 \pm 12.87$. While, the prevalence of overweight and obesity based on WHR were $22.6 \%$ and $35.5 \%$ respectively, with mean WHR $0.82 \pm 0.82$. This finding provides answer to the first research question.

Table 3. Mean total score of quality of life domains among study population $(n=310)$.

\begin{tabular}{ll}
\hline Quality of life domains & Mean \pm SD \\
\hline How would you rate your quality of life? & $74.44 \pm 17.47$ \\
How satisfied are you with your health? & $68.95 \pm 21.33$ \\
Quality of life domains & \\
Total score of physical health domain & $71.98 \pm 12.46$ \\
Total score of psychological domain & $64.76 \pm 13.73$ \\
Total score of social relationships domain & $73.02 \pm 17.10$ \\
Total score of environment domain & $66.94 \pm 14.01$ \\
Total score of WHOQOL-Brief scale & $70.01 \pm 11.31$ \\
\hline
\end{tabular}

Table 3 provides detailed description about how the study subjects score their quality of life base on mean score of 26 items of WHOQOL-Brief scale as well as the mean total score of quality of life domains (physical health domain, psychological domain, social relationships domain environment domain). As shows in the table, the mean score of how the participants rated their quality of life and their satisfaction with their health were $74.44 \pm 17.47$ and $68.95 \pm$ 21.33 respectively. The mean total score of the four domains from highest to lowest score were social relationships domain (73.02 \pm 17.10$)$, physical health domain (71.98 \pm 12.46$)$, environment domain $(66.94 \pm 14.01)$, and psychological domain $(64.76 \pm 13.73)$. The mean of total score of WHOQOL-Brief scale was $(70.01 \pm 11.31)$. The findings in this table in addition to finding in figure (1) revealed an answer to the third research question.

Table 4. Comparison between perception of weight and actual BMI among study population.

\begin{tabular}{|c|c|c|c|c|c|c|c|}
\hline \multirow{2}{*}{ Actual BMI } & \multicolumn{4}{|c|}{ Weight Perception } & \multirow{2}{*}{ Total } & \multirow{2}{*}{$\mathbf{X}^{2}$} & \multirow{2}{*}{$\mathbf{P}$} \\
\hline & Underweight & Normal weight & Over weight & Obese & & & \\
\hline \multicolumn{8}{|l|}{ Underweight } \\
\hline No & 3 & 4 & 9 & 2 & 18 & & \\
\hline$\%$ & $8.8 \%$ & $3.4 \%$ & $12.0 \%$ & $2.4 \%$ & $5.8 \%$ & & \\
\hline \multicolumn{8}{|l|}{ Normal weight } \\
\hline No & 5 & 42 & 13 & 47 & 107 & & \\
\hline$\%$ & $14.7 \%$ & $35.6 \%$ & $17.3 \%$ & $56.6 \%$ & $34.5 \%$ & & \\
\hline No & 8 & 33 & 26 & 26 & 93 & 50.52 & 0.00 \\
\hline$\%$ & $23.5 \%$ & $28.0 \%$ & $34.7 \%$ & $31.3 \%$ & $30.0 \%$ & & \\
\hline \multicolumn{8}{|l|}{ Obese } \\
\hline No & 18 & 39 & 27 & 8 & 92 & & \\
\hline$\%$ & $52.9 \%$ & $33.1 \%$ & $36.0 \%$ & $9.6 \%$ & $29.7 \%$ & & \\
\hline \multicolumn{8}{|l|}{ Total } \\
\hline No & 34 & 118 & 75 & 83 & 310 & & \\
\hline
\end{tabular}

Table 4: illustrates Comparison between perception of weight and actual BMI among study population. As can be seen clearly from the table, there was significant difference between participants' perception of their weight and the actual BMI as measured by the research at the time of data collection, $\mathrm{X}^{2}=50.52, \mathrm{P}=0.00$, that indication participants misperception of their weight. This result shows how the Saudi females perceive their weight, which answers the second research question.

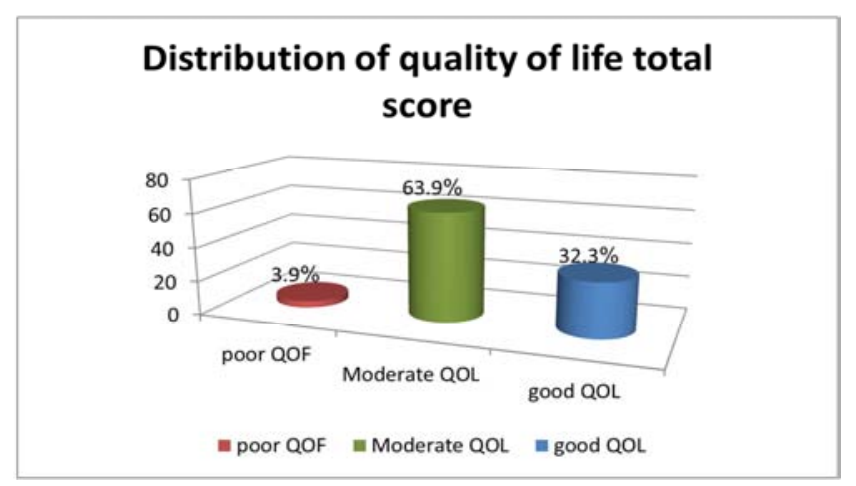

Figure 1. Distribution of quality of life total score.
Figure 1 displays frequency distribution of participants' total score of WHOQOL-Brief scale. As can be seen, 63.9\% of participants had moderate quality of life, $32.3 \%$ of them has good quality of life, while only $3.9 \%$ had poor quality of life.

Table 5. Correlations between age, body mass index, waist circumference, and waist -hip ratio and rating quality of life score, total score quality of life.

\begin{tabular}{lllll}
\hline & \multicolumn{2}{l}{ Rating quality of life item score } & \multicolumn{2}{l}{ Total score of quality of life } \\
\cline { 2 - 5 } & $\mathbf{r}$ & $\mathbf{p}$ & $\mathbf{r}$ & $\mathbf{p}$ \\
\hline BMI & $-.232^{* *}$ & .000 & $-.143^{*}$ & .012 \\
WC & $-.193^{* *}$ & .001 & $-.121^{*}$ & .033 \\
WHR & $-.154^{* *}$ & .007 & $-.142^{*}$ & .012 \\
\hline
\end{tabular}

* Correlation is significant at the 0.05 level (2-tailed).

** Correlation is significant at the 0.01 level (2-tailed).

As shows in table 3, Pearson correlation test revealed significant negative correlation between BMI and rating quality of life item and total score of quality of life, $\mathrm{P}=.000$ and .012, respectively. This finding indicated that, as BMI increases the quality of life decreases. Moreover, a significant negative correlation between WC, WHR, and rating quality of life item, $\mathrm{P}=.001$ and .007 , respectively. Also, a significant negative correlation between WC, WHR 
and total score quality of life $\mathrm{P}=.033$ and .012 , respectively. This finding indicated that, as WC and WHR increase the quality of life decreases, the findings provide answer to the fourth research question.

Table 6. Comparison of total quality of life means score among categories of body mass index, waist circumference and waist-hip ratio.

\begin{tabular}{|c|c|c|c|c|c|}
\hline \multicolumn{6}{|c|}{ Totals score of quality of life } \\
\hline BMI & Sum of Squares & df & Mean Square & $\mathbf{F}$ & Sig. \\
\hline Between Groups & 1205.502 & 3 & 401.834 & & \\
\hline Within Groups & 38318.775 & 306 & 125.225 & 3.209 & .023 \\
\hline Total & 39524.277 & 309 & & & \\
\hline Waist circumference & Sum of Squares & $\mathrm{df}$ & Mean Square & $\mathrm{F}$ & Sig. \\
\hline Between Groups & 724.092 & 2 & 362.046 & & \\
\hline Within Groups & 38800.185 & 307 & 126.385 & 2.865 & .059 \\
\hline Waist-hip ratio & Sum of Squares & df & Mean Square & $\mathrm{F}$ & Sig. \\
\hline Between Groups & 525.519 & 2 & 262.760 & & \\
\hline Within Groups & 38998.758 & 307 & 127.032 & 2.068 & .128 \\
\hline Total & 39524.277 & 309 & & & \\
\hline
\end{tabular}

Table 6 provides the results of one way analysis of variance (Anova) that carried out to compare mean score of total quality of life among various categories of BMI, WC and WHR. The findings revealed statistically significant difference between categories of body mass index in total quality of life mean score, $\mathrm{f}=3.209, \mathrm{P}=.023$. Post hoc test that conducted after significant anova indicated that the total quality of life mean score was significantly lower among obese participant (mean $68.05 \pm 10.13$ ) compared to the participant with normal body mass index (mean $72.30 \pm$ 12.07). These results suggested that as body mass index increases the total quality of life mean score decreases. This finding is another support to fourth question's answer.

Regarding WC, Anova results showed that no significant difference in mean score of total quality of life among different cut of points of $\mathrm{WC}, \mathrm{f}=2.865, \mathrm{P}=.059$. Regarding WHR, Anova results revealed no significant difference in mean score of total quality of life among different cut of points of WHR, $\mathrm{f}=2.068, \mathrm{P}=.128$.

\section{Discussion}

The current study was carried out to estimate the prevalence of obesity and investigate the association between body mass index, waist circumference, waist-to-hip ratio and quality of life among Saudi Females. The data were collected from eligible 310 subjects who agree to participate in the study, who met the inclusion criteria and who provide complete data.

The mean age of study population was $28.27 \pm 7.89$. The prevalence of obesity based on BMI, WC, and WHR were $29.7 \%, 34.2 \%$ and $35.5 \%$ respectively, that results general and abdominal obesity. These findings were supported by the previous studies. [31] found that the prevalence of obesity based on body mass index was $30.6 \%$ among adult Saudi females. Similarly, [3] reported that prevalence of obesity among Saudi females $44 \%$ and $33.5 \%$ respectively. The current findings also were supported by other studies. [32] reported that about $48 \%$ of adult women in Iran were overweight or obese based on body mass index and $43.4 \%$ of women had abdominal obesity. Additionally, [33] found that prevalence of obesity was 36\% among Tanzania women.

The perception of one's body-weight is an essential determinant of weight-related behaviors [34]. Overweight individuals who do not recognize themselves as overweight might be unaware to involve in weight control behaviors [35]. Misperception of body-weight can be a predisposing factor for obesity. The results of current study shown a significant difference between participants' perception of their weight and the actual BMI, $\mathrm{X}^{2}=50.52, \mathrm{P}=0.00$, that indicated participants misperception of their weight. The study findings were constant with the findings of [36] in study carried out in Dammam in the eastern province of KSA, reported that many severely obese women considered themselves as normal weight. In an another study conducted among university female students in Riyadh (KSA) by [37] who found that $17.4 \%$ of the obese and $54.2 \%$ of the overweight perceived themselves as of normal weight. Similarly, [38] found that only $23 \%$ of university Saudi females showed an agreement between their actual, perceived, and ideal body shape. Moreover, Alfa et al. (2012) in Tanzania reported that $38 \%$ of overweight women perceived themselves as overweight or obese.

Quality of life (QOL) is individual's perception of daily life quality. WHOQOL-Brief scale was used to assess the quality of life of study population. The results of current study indicated that the mean score of how the participants rated their quality of life and their satisfaction with their health were $74.44 \pm 17.47$ and $68.95 \pm 21.33$ respectively. Social relationships domain was the highest score, the mean $=73.02 \pm 17.10$, while lowest score was psychological domain, the mean $=64.76 \pm 13.73$. The mean of total score of WHOQOL-Brief scale was $(70.01 \pm 11.31)$. Moreover, $63.9 \%$ of participants had moderate quality of life, $32.3 \%$ of them has good quality of life, while only $3.9 \%$ had poor quality of life. This result was to some extent different from those of [25], they reported that $67.8 \%$ adolescent Saudi females had good quality of life, $25.9 \%$ had moderate quality of life, while only $6.3 \%$ had poor quality of life, and the difference might be due to age difference between current study sample and their study sample.

Regarding the relationship between BMI, WC, and WHR 
and total score of quality of life as illustrated by Pearson correlation test, significant negative correlation was revealed between BMI, WC, and WHR, rating quality of life score item as well as total score quality of life as clearly presented in table 5. These findings indicating that quality of life decreases as BMI increase. The current results in congregant with [25] revealed significant decrease in quality of life among adolescent Saudi females with increased body mass. Similarly, [39] reported negative correlation between BMI and total score of quality of life among adult males and females in Brazil. Moreover, other studies were supported to the present study; the findings of [40] indicated negative association between body mass index, waist-hip ratio, body fat and health- related quality of life among Greek healthy adult males and females. [41], revealed significantly lower quality of life among adult population of high waist-hip ratio. On the other hand, the current study results of one way analysis of variance (Anova) revealed that WC, and WHR had not indicating significant effect of the total quality of life. This result might be due to that plumpness body shape is culturally considered as a preferred characteristic of feminine beauty in Arab societies as illustrated by [42].

\section{Conclusion}

General and abdominal obesity were highly prevalent among adult Saudi females as measured by BMI, WHR. Misperception of weight was revealed and minority of subjects had good quality of life. Obesity was associated with significant decrease in quality of life.

\section{Recommendation}

Effective health education strategies are required to help in increase females' awareness and perception of their weight, thus affecting their decisions and behaviors to minimize obesity and its negative influences on their health and consequently their quality of life.

\section{References}

[1] Flegal K. M., Carrol M. D., Ogden C. L., and Curtin L. R. (2010). Prevalence and trends in obesity among US adults. JAMA; 303: 235-241.

[2] Pimenta F. B. C., Bertrand E., Mograbi D. C., Shinohara H., and Landeira-Fernandez J. (2015). The relationship between obesity and quality of life in Brazilian adults. Frontiers in Psychology; 6: 966.

[3] Al-Nozha M. M., Al-Mazrou Y. Y., Al-Amateur M. A., Arafah M. R., Khalil M. Z., Khan N. B., Al-Marzouki K., Abdullah M. A., Al-Khadra A. H., Al-Harthi S. S., Al-Shahid M. S., AlMobeireek A., and Nouh M. S. (2005). Obesity in Saudi Arabia. Saudi Med J; May, 26 (5): 824-9.

[4] Al Othaimeen Al., Al-Nozha M., and Osman A. K. (2007). Obesity an emerging problem in Saudi Arabia; analysis of data from national nutrition survey. East Mediterr Health J; 13 (2): 441 .
[5] Aldaqal S. M. and Sehlo M. G. (2013). Self-esteem and quality of life in adolescents with extreme obesity in Saudi Arabia: the effect of weight loss after laparoscopic sleeve gastrectomy. General Hospital Psychiatry; 35: 259-264.

[6] Must A., Spadano J., Coakley E. H., Field A. E., Colditz, G., and William H. Dietz W. H. (1999). The disease burden associated with overweight and obesity. The Journal of American Medical Association; 282 (16): 1523-1529.

[7] Connolly B. S., Barnett C., Vogt K., Li T., Stone J, and Boyd N. (2002). A meta-analysis of published literature on waist-tohip ratio and risk of breast cancer. Nutr Cancer; 44: 127-138.

[8] Hainer V, Toplak, H, and Mitrakou A. (2008). Treatment modalities of obesity. Diabeties care; 31 (Supplement 2), S269-S277.

[9] Kulie T., Slattengren A., Redmer J., Counts H., Eglash A., and Schrager S. (2011). Obesity and Women's Health: An Evidence-Based Review. J Am Board Fam Med; JanuaryFebruary, 24 (1) 75-85.

[10] Hu F. B. (2003). Overweight and obesity in women: health risks and consequences. J Womens Health (Larchmt); 12 (2): 163-72.

[11] Memish Z. A., El Bcheraoui C., Tuffaha M., Robinson M., Daoud F., Jaber S., Mikhitarian S., Al Saeedi M., AlMazroa M. A., Mokdad A. H., and Al Rabeeah A. A., (2014). Obesity and Associated Factors - Kingdom of Saudi Arabia, 2013. Prev Chronic Dis; 11: 140236.

[12] Welborn T. A. and Dhaliwal S. S. (2007). Preferred clinical measures of central obesity for predicting mortality. Eur J Clin Nutr; 61: 1373-1379.

[13] Jansses I., Katzmarzyk P. T, and Ross P. (2004). Waist circumference and not body mass index explains obesityrelated health risk. Am J Clin Nutr.; 79, 379-384.

[14] Bigaard J., Frederiksen K., Tjønneland A., Thomsen B. L., Overvad K., Heitmann B. L. et al. (2005). Waist circumference and body composition in relation to all-cause mortality in middle-aged men and women. Int J Obes (Lond); $29,778-784$.

[15] Huxley R., Mendis S., Zheleznyakov E., Reddy S. and Chan J (2010). Body mass index, waist circumference and waist: hip ratio as predictors of cardiovascular risk-a review of the literature. European Journal of Clinical Nutrition; 64: 16-22.

[16] De Koning L., Merchant A. T, Pogue J., and Anand S. S. (2007). Waist circumference and waist-to-hip ratio as predictors of cardiovascular events: meta-regression analysis of prospective studies. Eur Heart J; 28: 850-856.

[17] World Health Organization. (1996). what quality of life? The WHOQOL Group. World Health Organization Quality of Life assessment. World Health Forum; 17: 354-356.

[18] Tessier A., Zavorsky G. S., Kim D. J., Carli F., Christou N., Nancy E., and Mayo N. E. (2012). Understanding the determinants of weight-related quality of life among bariatric surgery candidates. Journal of Obesity; Vol. 2012, Article ID 713426, 9 pages.

[19] Bullinger M., Anderson R., Cella D., and Aaronson N. (1993). Developing and evaluating cross-cultural instruments from minimum requirements to optimal models. Quality of Life Research; 2 (6): 451-459. 
[20] Najim A. A. (2014). Effect of intervention educational programs on improving quality of life among overweight / obese university students in Gaza Strip. Open Journal of Nursing; 4: 886-895.

[21] Al-Haqwi A. I., Al-Nasir M., Ahmad N., Masaudi E., Alotaibi S. S., and Hamad B. (2015). Obesity and overweight in a major family practice center, central region, Saudi Arabia. Saudi Journal of obesity, 3 (1): 12-17.

[22] Hlatky M. A., Chung S. C., Escobedo J., Hillegass W. B., Melsop K, Rogers, W, et al. (2010). The effect of obesity on quality of life in patients with diabetes and coronary artery disease. Am. Heart J, 159: 292-300.

[23] Buttitta M., Iliescu C., Rousseau A., and Guerrien, A. (2014). Quality of life in overweight and obese children and adolescents: a literature review. Qual. Life Res. 23: 11171139 .

[24] McLaughlin L., and Hinyard L. J. (2014). The relationship between health-related quality of life and body mass index. West J Nurs Res; 36 (8): 989-1001.

[25] Habib F., ALFozan H., Barnawi N., Al Motairi W., Al Anizy A. H., Al Anizy A. S., Al Unizi A. E., and Al Anazi M. H. (2015). Relationship between body mass index, self-esteem and quality of life among adolescent Saudi female. Journal of Biology, Agriculture and Health care, 5 (10): 130-139.

[26] Al Senany S. and Al Saif A. (2015). Assessment of physical health status and quality of life among Saudi older adults. Phys Ther Sci. 27 (6): 1691-1695.

[27] WHOQOL group (1998). Development of the WHO-QOL BREF quality of life assessment. Psychological Medicine, 28: 551-558.

[28] WHOQOL Manual-Body.doc, updated (2005). Geneva, World Health Organization.

[29] WHO Expert Consultation Report (2008). Waist circumference and waist-hip ratio. Geneva, World Health Organization.

[30] World Health Organization (1998). Obesity - Preventing and Managing the Global Epidemic: Report of a WHO Consultation on Obesity. Geneva, World Health Organization.

[31] Rasheed P., Abou-Hozaifa B. M., and Khan A. (1994). Obesity among young Saudi female adults: a prevalence study on medical and nursing students. Public Health, 108 (4): 28994.

[32] Kelishadi R., Alikhani S., Delavari A., Alaedini F., Safaie A., and Hojatzadeh E. (2008). Obesity and associated lifestyle behaviors in Iran: findings from the first national non- communicable disease risk factor surveillance survey. Public Health Nutr.; 11: 246-51.

[33] Muhihi A. J., Njelekela M. A., Mpembeni R., Mwiru R. S., Mligiliche N., and Mtabaji J. (2012) Obesity, overweight, and perceptions about body weight among middle-aged adults in Dar es Salaam, Tanzania. International Scholarly Research Notices, Obesity Volume 2012 (2012), Article ID 368520, 6 pages.

[34] Dorosty A. R., Mehdikhani S., Sotoudeh, G., Rahimi A., Fariba Koohdani F., and Tehrani P. (2014). Perception of weight and health status among women working at health centres of Tehran. J Health Popul Nutr; 32 (1): 58-67.

[35] Yaemsiri S., Slining M., and Agawal S. K. (2011). Perceived weight status, overweight diagnosis, and weight control among US adults: the NHANES 2003-2008 study. International Journal of obesity; 35, 1063-1070.

[36] Rasheed P. (1998). Perception of body weight and selfreported eating and exercise behavior among obese and nonobese women in Saudi Arabia. Public Health; 112 (6): 409414 .

[37] Qauhiz N. M. A. (2010) "Obesity among Saudi female university students: dietary habits and health behaviours," Journal of the Egyptian Public Health Association; 85 (1-2): $45-59$.

[38] Khalaf A., Westergren A., Berggren V., Ekblom Ö., and AlHazzaa H. M. (2015). Perceived and ideal body image in young women in South Western Saudi Arabia. Journal of Obesity, Volume 2015 Article ID 697163, 7.

[39] Pimenta F. B. C., Daniel C. Mograbi D. C., Shinohara H. and Landeira-Fernandez J. (2015). The relationship between obesity and quality of life in Brazilian adults. Frontiers in Psychology; vol. 6: Article 966.

[40] Theodoropoulou E., Karteroliotis K., Koskolou M., and Nassis G. (2013). The association of total and abdominal obesity with health- related quality of in a sample of Greek healthy adult. Epidemiology Biostatistics and Public Health; 10 (2): e 8842 - 1 - e 8842 - 9 .

[41] Baldock K. L., Gill T. K., Chittleborough C. R., Taylor A. W. and the North West Adelaide health study Team (2007). The relationship between waist to hip and quality of life. Results from the North West AdelaideNorth Study. Stage 2, Epidemiological Series Report No. 24.

[42] Khawaja M. and Afifi-Soweid R. A. (2004). Images of body weight among young men and women: evidence from Beirut, Lebanon. Journal of Epidemiology and Community Health; 58 (4): 352-353. 